\title{
Cardiac magnetic resonance imaging in patients with Behçet's disease
}

\author{
Ali A. Ahmed' Samar Tharwat $^{1 *} \mathbb{E}$, Nihal M. Batouty², Ahmed El Bahy ${ }^{3}$, Ahmed M. Tawfik $^{2}$ and Dina A. Shahin ${ }^{1}$
}

\begin{abstract}
Background: Behçet's disease (BD) is a multisystemic vasculitis that may affect the heart. However, the incidence and nature of cardiac involvement in BD have not been clearly documented yet. The aim of this study was to delineate the cardiac magnetic resonance imaging (MRI) appearances of cardiac involvement in BD patients.

Methods: This cross-sectional observational study was carried out 30 BD patients without known cardiac disease. Patients were subjected to history taking, physical examination, echocardiography and cardiac MRI.

Results: At least one abnormality on cardiac MRI was observed in 20/30 patients (66.67\%). Myocardial oedema was observed in 3 patients (10\%) and late gadolinium enhancement in 1 patient (3.3\%). Pericardial effusion was found in 3 patients (10.0\%), global hypokinesia in 6 patients (20.0\%) and intra-cardiac thrombosis in only 1 patient (3.3\%). Pulmonary artery was dilated in 4 patients (13.3\%). Left ventricular (LV) and right ventricular (RV) end diastolic volume were altered in 4 patients (13.3\%) and 7 patients (23.3\%) respectively. LV and RV end systolic volume were abnormal in 7 patients (23.3\%) and 5 patients (16.7\%) respectively. There was aortic valve regurge in 2 patients (6.7\%), tricuspid valve regurge in 9 patients (30\%), and mitral valve regurge in 9 patients (30\%). Dilated left main coronary artery was found in 2 patients (6.7\%) and arrhythmogenic right ventricular dysplasia in only one patient 1 patient (3.3\%). On logistic regression analysis, BD activity index score was a significant predictor of cardiac abnormalities.
\end{abstract}

Conclusion: BD may cause cardiac abnormalities without clinical manifestations and cardiac MRI may represent a tool for early detection of these subtle abnormalities. Higher BD activity index scores are strongly linked to cardiac problems.

Keywords: Behçet's disease, Heart, Cardiac MRI

\section{Background}

Behçet disease (BD) is a chronic, relapsing inflammatory disorder of unknown etiology [1]. Although BD occurs worldwide, it is most prevalent along the "Silk road" region extending from Japan to the Middle Eastern countries [2]. The exact pathogenesis is still unknown, but it is a multifactorial disease classified as vasculitis. It may be

\footnotetext{
*Correspondence: samartharwat2000@yahoo.com

${ }^{1}$ Rheumatology and Immunology Unit, Internal Medicine Department, Faculty of Medicine, Mansoura University Hospital, Mansoura University, El Gomhouria St, Mansoura, Dakahlia Governorate, Egypt

Full list of author information is available at the end of the article
}

triggered by many environmental factors as infection in genetically predisposed persons [3].

$\mathrm{BD}$ was first described as a trisymptom complex of recurrent oral and genital ulcers and uveitis [4] and later recognized as a multisystem disease with neurological, pulmonary, gastrointestinal, musculoskeletal, vascular and cardiac involvement [5].

Venous pathology and thrombotic complications are hallmarks of BD. However, cardiac involvement is rare and underestimated [6]. All cardiac layers may be involved resulting in pericarditis, myocarditis, endocarditis, intracardiac thrombosis and valvular disease [7]. Early recognition of cardiac involvement is important being associated with poor prognosis. There are only few 
data on cardiac manifestations in BD. Additionally, routine methods assessing heart involvement in BD patients such as echocardiography are not sensitive nor specific [8].

Cardiac magnetic resonance imaging (MRI) is a noninvasive, non-radiating safe modality that can be valuable in assessing cardiac structure and function [9]. The aims of the present study were to evaluate usefulness of cardiac MRI in BD patients without known cardiac disease and to detect areas of hyperenhancement after IV administration of gadolinium. To the best of our knowledge, this is the first study to investigate silent cardiac involvement in patients with BD using Cardiac MRI.

\section{Methods \\ Patients}

This is an observational analytical cross-sectional study conducted on 30 patients with BD. Patients were recruited from Rheumatology and Immunology unit at Mansoura University Hospital, Egypt between May 2018 to December 2019. All patients met the following inclusion criteria: (a) age $>18$ years (b) classified as having $\mathrm{BD}$ according to the International Criteria for Behcet's Disease (ICBD) [10] (c) BD duration more than one year (d) without known cardiac disease or manifestations. Exclusion criteria included: diabetes mellitus, hypertension, ischemic heart diseases, liver cell failure, overlap with other autoimmune diseases, and coexistent infection or malignancy. Patients with glomerular filtration rate below $30 \mathrm{ml} / \mathrm{min} / 1.73 \mathrm{~m}^{2}$ or had cardiac pacemaker or cochlear implants were also excluded from the start. The study protocol was approved by the Institutional Research Board of the Faculty of Medicine, Mansoura University (approval registration number: MS/18.02.44). The study was explained to all patients, and informed written consent was obtained from all of them before starting the study.

\section{Demographic, clinical and laboratory data}

For the included patients, sex, age and BD duration were recorded. $\mathrm{BD}$ cumulative manifestations affecting the eye, gastrointestinal tract, joints, skin, blood vessels and central nervous system were evaluated and registered by an experienced rheumatologist. BD activity within the past 4 weeks was also evaluated using Behçet's Disease Current Activity Form 2006 (BDCAF) (http://www. behcet.ws).

The following investigations were evaluated and recorded at the same day of clinical assessment: complete blood count $(\mathrm{CBC})$, erythrocyte sedimentation rate (ESR), C-reactive protein (CRP) and serum creatinine (SCr).

\section{Transthoracic echocardiographic evaluation}

Transthoracic echocardiographic evaluation of each patient was done by an experienced internist who was blinded to the clinical data. All patients were scanned by the same physician using commercial imaging analysis software (Philips Affiniti 50) with high frame rates (>60 frames/s) and evaluated according to the American Society of Echocardiography [11].

\section{Cardiac MRI protocol}

Each patient was evaluated by cardiac MRI within $24 \mathrm{~h}$ after clinical and echocardiographic assessment. Cardiac MRI was performed on a 1.5-T scanner (Philips Ingenia, Best, Netherlands). Retrospective ECG gating was used, and sequences were obtained with breath hold. Routine cine steady-state free-precession (SSFP) sequence was used to obtain a stalk of contiguous slices in the shortaxis, axial, three chamber and four chambers. Parameters were $\mathrm{TR}=3.2 \mathrm{~ms}, \mathrm{TE}=1.6 \mathrm{~ms}$, field of view (FOV) 350 $\mathrm{mm}^{2}$, slice thickness $=5 \mathrm{~mm}$, no slice gap. Intravenous contrast agent (DOTAREM, Magnevest) was injected at a dose of $0.2 \mathrm{mmol} / \mathrm{kg}$. After $10-15 \mathrm{~min}$ of contrast injection, T1-weighted inversion recovery sequence (PSIRTFE-BH) was acquired in the short axis and 4 chamber planes with the following parameters: FOV $350 \times 350$ $\mathrm{mm}^{2}$, slice thickness $8-10 \mathrm{~mm}$, acquisition matrix $220 \times 176$, voxel size $1.6 \times 1.9 \times 10$, TR/TE $6.1 \mathrm{~ms} / 3 \mathrm{~ms}$, flip angle $25^{\circ}$, and inversion time (TI) $250-425 \mathrm{~ms}$. T2-weighted images were acquired in the short axis plane with a triple inversion recovery fast spin echo with the following parameters: TR, $1500 \mathrm{~ms}$, TE $30 \mathrm{~ms}$, FA 90 FOV $350 \times 350 \mathrm{~mm}^{2}$, matrix 196-149 and slice thickness $8 \mathrm{~mm}$.

Cardiac morphology and function were evaluated by an experienced radiologist blinded to echocardiography reports, using the dedicated cardiac MR software. Left ventricle and right ventricle volume and function were assessed by manually tracing the endocontours at endsystole and end-diastole. No sedation was used, and all patients were in sinus rhythm during the examination.

\section{Cardiac MRI Post processing and image analysis}

Cardiac morphology and function were evaluated by an experienced radiologist, blinded to echocardiography reports, using extended MR 130 Workspace 2.6.3.5, Philips medical systems Netherland. Semi-automated method was used to trace the endocardial contours of both left and right ventricles and LV epicardial contours on each slice from base to apex on short axis plane for left ventricle and axial plane for right ventricle on end systole and end diastole. The end diastolic volume (EDV) and end systolic volume (ESV) were recorded. The Stroke 
volume (SV) was obtained as the difference between EDV and ESV. The ejection fraction (EF) is the SV/EDV. The end diastolic wall mass of left ventricle (LVM) was calculated as the total myocardial volume multiplied by specific gravity of myocardial tissue $(1.05 \mathrm{~g} / \mathrm{mL})$. Both ventricular end diastolic volume indexed (EDVi) and the left ventricular mass indexed (LVMi) were measured by dividing the EDV and myocardial mass by the BSA. Late contrast enhancement and myocardial oedema were evaluated on PSIR-TFE-BH sequence and T2 with triple inversion recovery sequence.

\section{Statistical analysis}

The collected data were coded, processed, and analysed using IBM SPSS for Windows version 24 (IBM Corp., Armonk, NY). After examining the distribution of continuous variables for normality using the Shapiro-Wilk test, data were expressed as mean and standard deviation if normally distributed or as median, minimum, and maximum if not normally distributed. Qualitative data were presented as frequencies and relative percentages. The Mann-Whitney test and independent samples t-test were used to compare continuous variables. The chisquare test was used to assess the differences between qualitative variables. The Spearman's rank-order correlation was used to determine the strength and direction of a linear relationship between two non-normally distributed continuous variables and/or ordinal variables. Logistic regression analysis was carried out to identify the potential predictors for cardiac MRI abnormalities. A ROC curve was also generated and the area under the curve (AUC) was calculated for BDCAF score to identify the cut off points above which cardiac MRI abnormalities are likely. $P$ values of $\leq 0.05$ were considered significant.

\section{Results}

\section{Patients' characteristics and echocardiographic findings}

A total of $30 \mathrm{BD}$ patients were included in the study. The patients' characteristics and transthoracic echocardiographic findings are described in Table 1 . Among the studied patients, $21(70 \%)$ were males and their mean age was 32.3 years (SD 8.9). The median duration of BD was 3 years with a range from 1.5-7 years. Echocardiography detected tricuspid valve regurge in 8 patients $(26.7 \%)$ and global myocardium hypokinesia in 6 patients (20\%).

\section{Cardiac MRI evaluation}

Cardiac MRI showed at least one abnormality in 25 $(83.33 \%)$ of the studied $30 \mathrm{BD}$ patients. The main cardiac MRI findings are shown in Table 2. Increased signal
Table 1 Demographic, clinical, laboratory, echocardiographic and treatment characteristics of patients $(n=30)$

\begin{tabular}{|c|c|}
\hline Characteristic & Value \\
\hline \multicolumn{2}{|l|}{ Demographic and clinical characteristics } \\
\hline Age (years), $M \pm S D$ & $32.3 \pm 8.9$ \\
\hline \multicolumn{2}{|l|}{ Sex } \\
\hline Male, n (\%) & $21(70)$ \\
\hline Female, n (\%) & $9(30)$ \\
\hline Behçet's disease duration (years), median (min-max) & $3(1.5-7)$ \\
\hline Height (cm), $M \pm S D$ & $171.03 \pm 5.49$ \\
\hline Weight (kg), $M \pm S D$ & $75.37 \pm 9.22$ \\
\hline $\mathrm{BMI}\left(\mathrm{kg} / \mathrm{m}^{2}\right), \mathrm{M} \pm \mathrm{SD}$ & $25.82 \pm 3.37$ \\
\hline Heart rate (bpm), $\mathrm{M} \pm \mathrm{SD}$ & $89.50 \pm 7.69$ \\
\hline $\mathrm{SBP}(\mathrm{mmHg}), \mathrm{M} \pm \mathrm{SD}$ & $127.5 \pm 6.53$ \\
\hline $\mathrm{DBP}(\mathrm{mmHg}), \mathrm{M} \pm \mathrm{SD}$ & $78.33 \pm 9.49$ \\
\hline Behcet disease activity index score, $\mathrm{M} \pm \mathrm{SD}$ & $4.60 \pm 1.4$ \\
\hline$\leq 4, \mathrm{n}(\%)$ & $15(50)$ \\
\hline$>4, \mathrm{n}(\%)$ & $15(50)$ \\
\hline \multicolumn{2}{|l|}{ Cumulative manifestations of Behcet disease, n (\%) } \\
\hline Orogenital Ulcers & $30(100)$ \\
\hline Uveitis & $23(76.7)$ \\
\hline Cutaneous manifestations & $11(36.7)$ \\
\hline Musculoskeletal manifestations & $10(33.3)$ \\
\hline Gastrointestinal tract manifestations & $1(3.3)$ \\
\hline Deep venous thrombosis & $4(13.3)$ \\
\hline \multicolumn{2}{|l|}{ Laboratory characteristics } \\
\hline \multicolumn{2}{|l|}{ Complete blood count } \\
\hline $\mathrm{Hb}(\mathrm{g} / \mathrm{dL}), \mathrm{M} \pm \mathrm{SD}$ & $11.83 \pm 1.01$ \\
\hline WBCs $\left(10^{3} / \mathrm{mm}^{3}\right), \mathrm{M} \pm \mathrm{SD}$ & $4.63 \pm 1.5$ \\
\hline $\operatorname{PLT}\left(10^{3} / \mathrm{mm}^{3}\right), \mathrm{M} \pm \mathrm{SD}$ & $222.8 \pm 53.6$ \\
\hline Serum creatinine $(\mathrm{mg} / \mathrm{dL}), \mathrm{M} \pm \mathrm{SD}$ & $0.91 \pm 0.11$ \\
\hline Erythrocyte sedimentation rate ( $\mathrm{mm} / \mathrm{hr}), \mathrm{M} \pm \mathrm{SD}$ & $35.33 \pm 10.08$ \\
\hline Positive C-reactive protein, n (\%) & $14(46.7)$ \\
\hline \multicolumn{2}{|l|}{ Echocardiographic findings } \\
\hline Ejection fraction (\%), $\mathrm{M} \pm \mathrm{SD}$ & $59.73 \pm 5.09$ \\
\hline Pericardial effusion, n (\%) & $2(6.7)$ \\
\hline Global hypokinesia, n (\%) & $6(20)$ \\
\hline Aortic valve regurge, $\mathrm{n}(\%)$ & $1(3.3)$ \\
\hline Tricuspid valve regurge, $\mathrm{n}(\%)$ & $8(26.7)$ \\
\hline Intra-cardiac thrombosis, n (\%) & $1(3.3)$ \\
\hline \multicolumn{2}{|l|}{ Medications used for treatment, n (\%) } \\
\hline Colchicine & $30(100)$ \\
\hline Steroids & $30(100)$ \\
\hline Azathioprine & $14(46.7)$ \\
\hline Cyclosporine & $14(46.7)$ \\
\hline Anticoagulants & $5(16.7)$ \\
\hline Biological agents & $10(33.3)$ \\
\hline Dose of steroids (mg /day), median (min-max) & $20(0-60)$ \\
\hline
\end{tabular}

BMI, body mass index; DBP, diastolic blood pressure; SBP, systolic blood pressure 
Table 2 Findings of cardiac MRI of the studied Behçet's patients $(n=30)$

\begin{tabular}{|c|c|}
\hline Findings of cardiac MRI & $\begin{array}{l}\text { The study } \\
\text { patients } \\
(n=30)\end{array}$ \\
\hline \multicolumn{2}{|l|}{ End diastolic volume (ml), $\mathrm{M} \pm \mathrm{SD}$} \\
\hline Left ventricle & $79.36 \pm 19.71$ \\
\hline Right ventricle & $85.46 \pm 23.09$ \\
\hline \multicolumn{2}{|l|}{ End systolic volume (ml), $M \pm S D$} \\
\hline Left ventricle & $31.59 \pm 9.59$ \\
\hline Right ventricle & $40.84 \pm 12.15$ \\
\hline \multicolumn{2}{|l|}{ Stroke volume $(\mathrm{ml}), \mathrm{M} \pm \mathrm{SD}$} \\
\hline Left ventricle & $46.74 \pm 12.29$ \\
\hline Right ventricle & $46.27 \pm 11.53$ \\
\hline \multicolumn{2}{|l|}{ Ejection fraction (\%), $\mathrm{M} \pm \mathrm{SD}$} \\
\hline Left ventricle & $60.20 \pm 5.81$ \\
\hline Right ventricle & $53.70 \pm 4.74$ \\
\hline End diastolic wall mass $\left(\mathrm{g} / \mathrm{m}^{2}\right), \mathrm{M} \pm \mathrm{SD}$ & $61.46 \pm 11.2$ \\
\hline \multicolumn{2}{|l|}{ Signs of myocarditis, n (\%) } \\
\hline Myocardial edema & $3(10)$ \\
\hline Late gadolinium enhancement & $1(3.3)$ \\
\hline \multicolumn{2}{|l|}{ Cardiac valves, n (\%) } \\
\hline Aortic valve regurge & $2(6.7)$ \\
\hline Pulmonary valve regurge & 0 \\
\hline Tricuspid valve regurge & $9(30)$ \\
\hline Mitral valve regurge & $9(30)$ \\
\hline \multicolumn{2}{|l|}{ Blood vessels } \\
\hline Mid ascending aorta diameter $(\mathrm{mm}), \mathrm{M} \pm \mathrm{SD}$ & $28.18 \pm 3.07$ \\
\hline Aortic sinus root diameter $(\mathrm{mm}), \mathrm{M} \pm \mathrm{SD}$ & $29.98 \pm 2.76$ \\
\hline Main pulmonary artery diameter $(\mathrm{mm}), \mathrm{M} \pm \mathrm{SD}$ & $23.74 \pm 3.45$ \\
\hline Pulmonary /aortic ratio, $\mathrm{M} \pm \mathrm{SD}$ & $0.80 \pm 0.16$ \\
\hline Right pulmonary artery diameter $(\mathrm{mm}), \mathrm{M} \pm \mathrm{SD}$ & $16.09 \pm 2.24$ \\
\hline Left pulmonary artery diameter $(\mathrm{mm}), \mathrm{M} \pm \mathrm{SD}$ & $16.71 \pm 2.38$ \\
\hline Increased Pulmonary /aortic ratio, n (\%) & $3(10)$ \\
\hline Dilated main pulmonary artery, n (\%) & $4(13.3)$ \\
\hline $\begin{array}{l}\text { Bilateral pulmonary artery aneurysm and embolism, } \\
\text { n (\%) }\end{array}$ & $1(3.3)$ \\
\hline $\begin{array}{l}\text { Dilated left main coronary artery (coronary aneurysm), } \\
\mathrm{n}(\%)\end{array}$ & $2(6.7)$ \\
\hline SVC thrombosis & $1(3.3)$ \\
\hline \multicolumn{2}{|l|}{ Other findings, $\mathrm{n}(\%)$} \\
\hline Pericardial effusion & $3(10)$ \\
\hline Global hypokinesia & $6(20)$ \\
\hline Arrythmogenic right ventricular dysplasia* & $1(3.3)$ \\
\hline Right ventricular thrombus & $1(3.3)$ \\
\hline
\end{tabular}

SVC, Superior vena cava

*Major criterion of ARVD by MRl; dyskinesia of right ventricular free wall with right ventricular end diastolic volume indexed to body surface area more than $110 \mathrm{ml} / \mathrm{m}^{2}$

intensity on T2 weighted images (Fig. 1) was found in 3 patients (10\%) while myocardial delayed contrast enhancement was detected in only one patient (3.3\%).
Tricuspid and mitral valves showed evidence of regurge in 9 patients $(30 \%)$. Four of the 30 studied patients (13.3\%) showed dilatation at the main pulmonary artery while only one patient (3.3\%) showed aneurysmal dilatation and thrombosis of both right and left pulmonary arteries. Aneurysmal dilatation was observed at the left main coronary artery in 2 patients (6.7\%). Superior vena cava (SVC) was thrombosed in only 1 patient (3.3\%).

Pericardial effusion was detected in 3 patients (10\%). Additionally, global myocardium hypokinesia was present in 6 patients $(20 \%)$. The right ventricle showed evidence of thrombosis in 1 patient (3.3\%), and arrhythmogenic ventricular dysplasia in another 1 patient (3.3\%).

No significant difference between patients with and without cardiac MRI abnormalities when compared regarding demographic, clinical and therapeutic data as shown in Table 3.

For prediction of cardiac MRI abnormalities, logistic regression analysis was carried out. Diastolic blood pressure and BDCAF score were the most significant predictors for cardiac MRI abnormalities (Table 4). As shown in Fig. 2 the AUC of BDCAF score revealed that a cut off value of $>6$ identifying the probability of cardiac MRI abnormalities with $84 \%$ sensitivity and $60 \%$ specificity.

\section{Echocardiography versus cardiac MRI in detecting cardiac abnormalities}

When we explored the performance of echocardiography in heart evaluation compared to cardiac MRI in BD patients, the results showed sensitivity of $64 \%$, specificity of $100 \%$, positive predictive value (PPV) of $100 \%$, negative predictive value of $37.5 \%$ and accuracy of $70 \%$. Kappa agreement was 0.372 indicating slight agreement $(P=0.45)$.

\section{Discussion}

$\mathrm{BD}$ is a rare chronic autoinflammatory disorder that is usually seen along the Silk road including the Middle East and Far-east Asia [12]. It is characterized by four main symptoms of recurrent oral aphthous ulcers, genital ulcers, cutaneous manifestations, and ocular symptoms [13]. Cardiac involvement have been reported in about $6 \%$ of BD patients and may be subclinical [14]. Cardiac MRI is a non-invasive modality that can evaluate cardiac function and structure [15]. In the present study, we used cardiac MRI to evaluate cardiac abnormalities in a group of $30 \mathrm{BD}$ patients with no known cardiac disease.

To the best of our knowledge, this is the first detailed study of cardiac abnormalities encountered in patients with BD, which utilizes cardiac MRI. Previous studies in the literature used echocardiography to analyze the spectrum of cardiac involvement in BD patients [16-18]. 

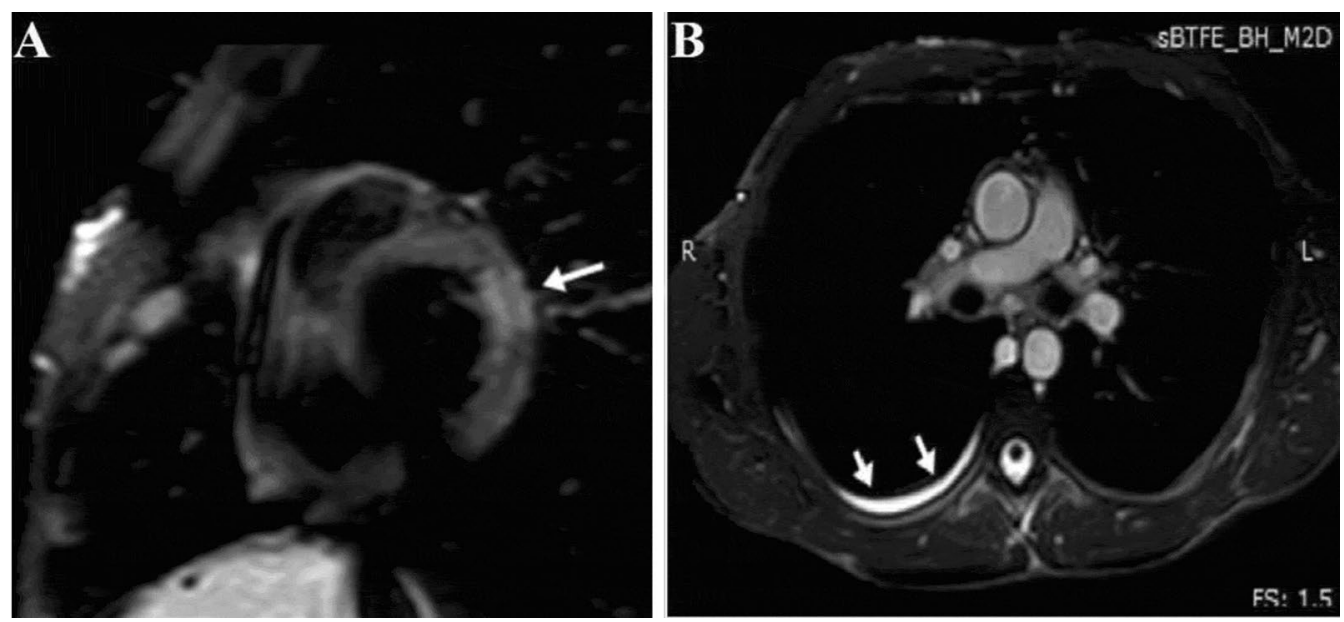

Fig. 1 Cardiac MRI of a 33-year-old male patient with Behcet's disease with $\mathbf{A}$ small patchy area of myocardial edema in lateral segment of basal myocardium of left ventricle in cardiac MRI T2 edema sequence short axis view and $\mathbf{B}$ small right sided pleural effusion in Cardiac MRI cine SSFP axial view

The main results of this study are as the following; first, the majority of BD patients (83\%) had at least one abnormality on cardiac MRI. Second, cardiac MRI enabled us to evaluate the pattern of these cardiac abnormalities. Third, cardiac MRI is more sensitive than echocardiography in detecting any cardiac abnormalities in $\mathrm{BD}$ patients. Lastly, higher scores of BDCAF are highly suggestive of cardiac abnormalities.

One of the most striking findings to emerge from this study is the high prevalence of detected subtle cardiac abnormalities. Pathological cardiac findings were detected in $83 \%$ of our study patients. However, in the study by Geri et al.[14], cardiac lesions were found in only $6 \%$ of a cohort of 807 patients with BD. This variability may be attributed to the different tools used for assessment of the heart. These results suggest that heart affection in BD may be underestimated, and cardiac MRI is more sensitive in detecting any subtle cardiac abnormalities.

Cardiovascular involvement is a remarkable systemic affection of BD [19] and may be overlooked. Aktürk E and coworkers evaluated the left atrium using real-time three-dimensional echocardiography (RT3DE) in $30 \mathrm{BD}$ patients with no cardiac symptoms and found significant impairment in left atrium volumes and mechanical functions in BD patients [17].

Myocardial edema has been detected in $10 \%$ of our patients. Additionally, one of these patients showed late gadolinium enhancement. These findings are highly suggestive of acute myocardial injury mostly myocarditis. Myocarditis is extremely rare in patients with BD [20, $21]$ and may contribute to cardiomegaly and cardiac fibrosis [22]. Cardiac MRI has emerged as a noninvasive diagnostic tool for early detection of myocarditis [23]. Kechida et al. have recently reported a case of BD with chest pain related to myocarditis that documented by cardiac MRI in spite of normal echocardiography [24].

Our results cast a new light on endocardial involvement in $\mathrm{BD}$ as valvular regurgitation was frequently observed in our cohort. The most frequently affected valves were the tricuspid and mitral valves ( $9 / 30$ patients) followed by the aortic valve (2/30 patients). Endocardial involvement was also identified in previous studies [14, 25-28]. A similar pattern of results was also obtained by another study; wherein a cross-sectional study evaluated $35 \mathrm{BD}$ patients using transesophageal echocardiography and revealed that mitral valve prolapse, and mitral regurgitation are the most frequent common findings of cardiac involvement in patients with BD [29].

The current study revealed dilated pulmonary artery in 4 cases and one case with bilateral pulmonary aneurysm and embolism. Pulmonary artery involvement is rare, it occurs in 1 to $7.7 \%$ of BD patients [30]. Pulmonary artery aneurysm with or without thrombosis is a typical feature of $\mathrm{BD}[31,32]$.

Coronary arteries are rarely involved by aneurysms formation in vasculitis [33-35] and usually observed in Kawasaki disease [36]. In a case-control study on 476 BD patients, coronary aneurysm were present in only 9 patients [37]. Similarly, we have demonstrated coronary aneurysm in 3 patients only. Notably, they were all asymptomatic.

Our cohort revealed one case of superior vena cava (SVC) thrombosis. Involvement of great veins is a welldefined but rare complication of BD [38]. SVC thrombosis occurs in $2 \%$ of $B D$ patients [38]. 
Table 3 Comparison between the studied patients with normal and abnormal cardiac MRI

\begin{tabular}{|c|c|c|c|}
\hline Variables & $\begin{array}{l}\text { With normal cardiac MRI } \\
\begin{array}{l}\mid n=5( \\
(\%=16.67)\end{array}\end{array}$ & $\begin{array}{l}\text { With abnormal cardiac MRI } \\
(n=25( \\
(\%=83.33)\end{array}$ & $P$ value \\
\hline \multicolumn{4}{|l|}{ Demographic and clinical characteristics } \\
\hline Age (years), $M \pm S D$ & $26.0 \pm 2.65$ & $33.56 \pm 9.22$ & .084 \\
\hline \multicolumn{4}{|l|}{ Sex } \\
\hline Male, n (\%) & $2(40)$ & $19(76)$ & .109 \\
\hline Female, n (\%) & $3(60)$ & $6(24)$ & \\
\hline Behçet's disease duration (years), median (min-max) & $2(2-3)$ & $3(1-7)$ & .176 \\
\hline Height (cm), $\mathrm{M} \pm \mathrm{SD}$ & $171.6 \pm 4.77$ & $170.92 \pm 5.71$ & .723 \\
\hline Weight (kg), $M \pm S D$ & $74 \pm 8.22$ & $75.64 \pm 9.54$ & .723 \\
\hline $\mathrm{BMI}\left(\mathrm{kg} / \mathrm{m}^{2}\right), \mathrm{M} \pm \mathrm{SD}$ & $25.08 \pm 1.86$ & $25.96 \pm 3.6$ & 60 \\
\hline Heart rate (bpm), $\mathrm{M} \pm \mathrm{SD}$ & $88 \pm 4.47$ & $89.9 \pm 8.23$ & 641 \\
\hline $\mathrm{SBP}(\mathrm{mmHg}), \mathrm{M} \pm \mathrm{SD}$ & $124 \pm 5.47$ & $128.2 \pm 6.59$ & .19 \\
\hline $\mathrm{DBP}(\mathrm{mmHg}), \mathrm{M} \pm \mathrm{SD}$ & $70 \pm 7.07$ & $80 \pm 9.13$ & .806 \\
\hline \multicolumn{4}{|l|}{ Behcet disease activity index score, $\mathrm{M} \pm \mathrm{SD}$} \\
\hline$\leq 4, \mathrm{n}(\%)$ & $1(20)$ & $14(56)$ & .33 \\
\hline$>4, n(\%)$ & $4(80)$ & $11(44)$ & \\
\hline \multicolumn{4}{|l|}{ Cumulative manifestations of Behcet disease } \\
\hline Orogenital Ulcers & $5(100)$ & $25(100)$ & 1 \\
\hline Uveitis & $4(80.0)$ & 19(76.0) & 1 \\
\hline Cutaneous manifestations & $1(20.0)$ & $10(40.0)$ & .63 \\
\hline Musculoskeletal manifestations & $2(40)$ & $8(32)$ & 1 \\
\hline Gastrointestinal tract manifestations & $1(20)$ & $1(4)$ & 1 \\
\hline Deep venous thrombosis & $1(20)$ & $3(12)$ & .53 \\
\hline \multicolumn{4}{|l|}{ Laboratory characteristics } \\
\hline \multicolumn{4}{|l|}{ Complete blood count } \\
\hline $\mathrm{Hb}(\mathrm{g} / \mathrm{dL}), \mathrm{M} \pm \mathrm{SD}$ & $11.90 \pm 0.74$ & $11.82 \pm 1.07$ & .88 \\
\hline $\operatorname{WBCs}\left(10^{3} / \mathrm{mm}^{3}\right), \mathrm{M} \pm \mathrm{SD}$ & $4.26 \pm 0.78$ & $4.71 \pm 0.71$ & .21 \\
\hline $\operatorname{PLT}\left(10^{3} / \mathrm{mm}^{3}\right), \mathrm{M} \pm \mathrm{SD}$ & $225.0 \pm 32.02$ & $222.36 \pm 57.48$ & .92 \\
\hline Serum creatinine (mg/dL), M $\pm S D$ & $0.86 \pm 0.09$ & $0.916 \pm 0.11$ & .312 \\
\hline Erythrocyte sedimentation rate $(\mathrm{mm} / \mathrm{hr}), \mathrm{M} \pm \mathrm{SD}$ & $33.0 \pm 12.04$ & $33.0 \pm 12.04$ & .58 \\
\hline Positive C-reactive protein, n (\%) & $2(40)$ & $12(48)$ & 1 \\
\hline \multicolumn{4}{|l|}{ Medications used for treatment, $\mathrm{n}(\%)$} \\
\hline Colchicine & $5(100)$ & $25(100)$ & 1 \\
\hline Steroids & $5(100)$ & $25(100)$ & 1 \\
\hline Azathioprine & $4(80)$ & $10(40)$ & .157 \\
\hline Cyclosporine & $1(20)$ & $11(44)$ & .62 \\
\hline Anticoagulants & $1(20)$ & $4(16)$ & 1 \\
\hline Biological agents & $1(20)$ & $9(36)$ & .64 \\
\hline
\end{tabular}

BMI, body mass index; DBP, diastolic blood pressure; Hb, hemoglobin; PLT, platelets; SBP, systolic blood pressure; WBCs, white blood cells

Among the studied $30 \mathrm{BD}$ patients, cardiac MRI showed evidence of pericardial effusion in 3 patients. Pericarditis seemed to be the most frequently observed cardiac feature in BD patients, occurring in up to $40 \%$ of cardiac involvement [14]. However severe pericardial effusion is not commonly observed [25].
Only 22 cases of intracardiac thrombosis associated with BD were reported from 1992 to 2010, most of the cases were limited to the right ventricle and atrium [14]. In this cohort, we have detected one case with evidence of right ventricular thrombosis.

We could not present any difference in BD activity between patients with and without cardiac 
Table 4 Logistic regression analysis for of independent predictors associated with abnormal cardiac MRI in the studied patients $(n=30)$

\begin{tabular}{llllll}
\hline Variable & $\begin{array}{l}\text { Odds ratio } \\
(\mathbf{9 5 \%} \mathbf{C l})\end{array}$ & \multicolumn{2}{l}{$\mathbf{9 5 \%} \mathbf{C l}$} & \multirow{2}{*}{$\boldsymbol{P}$ value } \\
& & $\mathbf{L L}$ & $\mathbf{U L}$ & \\
\hline Age/years & 1.25 & 0.97 & 1.59 & .08 \\
Sex (male) & 4.75 & 0.64 & 35.48 & .13 \\
Behcet disease duration & 1.88 & 0.72 & 4.96 & .19 \\
Heart rate & 1.04 & 0.85 & 1.27 & .74 \\
SBP & 1.32 & 0.98 & 1.79 & .07 \\
DBP & 1.28 & 1.03 & 1.59 & $.03^{*}$ \\
BMl & 1.26 & 0.83 & 1.92 & .28 \\
Behcet's disease activity index & 0.42 & 0.18 & 1.0 & $.05^{*}$ \\
Azathioprine & 0.17 & 0.007 & 4.03 & .270 \\
Cyclosporine & 0.79 & 0.02 & 33.18 & .902 \\
Anticoagulants & 0.81 & 0.03 & 23.56 & .904 \\
Biological agents & 1.44 & 0.03 & 66.77 & .853 \\
\hline
\end{tabular}

$\mathrm{BMI}$, body mass index; $\mathrm{Cl}$, confidence interval; $\mathrm{DBP}$, diastolic blood pressure; $\mathrm{LL}$, lower limit; SBP, systolic blood pressure; UL, upper limit $* P \leq 0.05$

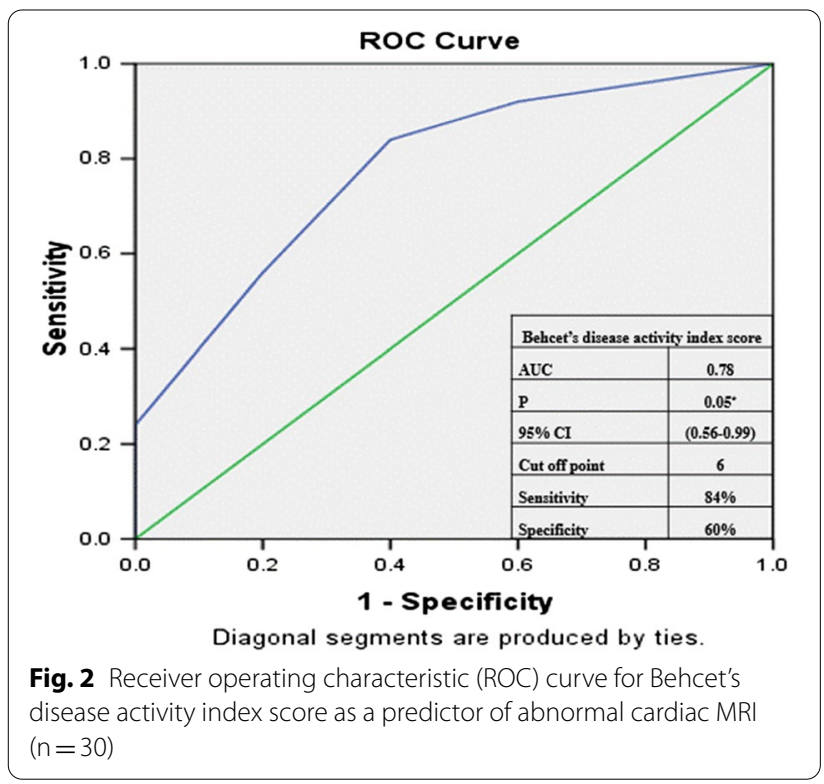

abnormalities. However, the score of BDCAF was among the most significant predictors of cardiac abnormalities in BD patients on logistic regression analysis. Others have shown that cardiac manifestations in BD patients are not proportional to systemic BD activity [39].

Finally, we admit that this study has some limitations; namely, the small sample size, the absence of a matched control group and the cross-sectional nature with only a single evaluation of the heart status in BD patients. Also, there was no information about serum level of important cardiac enzymes as troponin and CK-MB. Advanced cardiac MRI tools as T1/T2 mapping and extra-cellular volume (ECV) quantifications were not part of this study protocol. It would be highly favorable to perform future multi-parametric cardiac MRI studies on patients with BD. However, the detailed assessment of the functional and anatomical cardiac abnormalities and investigating the relation between these abnormalities and BD activity index score are strengths of this study.

\section{Conclusion}

BD may cause cardiac abnormalities without clinical manifestations and cardiac MRI may represent a tool for early detection of these subtle abnormalities. Higher BD activity index scores are strongly linked to cardiac problems. Echocardiography may be not enough for screening for cardiac involvement in BD patients and cardiac MRI is recommended especially in those with high $\mathrm{BD}$ activity index.

\section{Acknowledgements}

Not applicable

\section{Authors' contributions}

ST and DA conceived the hypothesis, provided clinical guidance, and interpretation of the findings, AA, NM and ST and performed data collection and drafted the manuscript. AE and AM participated in study design, conducted data analysis, and edited the final manuscript. The authors read and approved the final manuscript.

Funding

None.

Availability of data and materials

The outputs are available from the authors upon request.

\section{Declarations}

Ethics approval and consent to participate

The study protocol was approved by the Institutional Research Board of the Faculty of Medicine, Mansoura University (approval registration number: $\mathrm{MS} / 18.02 .44)$

\section{Consent for publication}

Not applicable.

\section{Competing interests}

All authors have no competing interests.

\section{Author details}

${ }^{1}$ Rheumatology and Immunology Unit, Internal Medicine Department, Faculty of Medicine, Mansoura University Hospital, Mansoura University, El Gomhouria St, Mansoura, Dakahlia Governorate, Egypt. ${ }^{2}$ Diagnostic and Interventional Radiology Department, Faculty of Medicine, Mansoura University, Mansoura, Dakahlia Governorate, Egypt. ${ }^{3}$ Mansoura University Nephrology and Dialysis Unit, Internal Medicine Department, Faculty of Medicine, Mansoura University, Mansoura, Dakahlia Governorate, Egypt.

Received: 18 August 2021 Accepted: 24 November 2021

Published online: 07 December 2021 


\section{References}

1. Khairallah M, Accorinti M, Muccioli C, Kahloun R, Kempen JH. Epidemiology of Behçet disease. Ocul Immunol Inflamm. 2012;20(5):324-35. https://doi.org/10.3109/09273948.2012.723112.

2. Alpsoy EJT. Behcet's disease: a comprehensive review with a focus on epidemiology, etiology and clinical features, and management of mucocutaneous lesions. J Dermatol. 2016;43(6):620-32. https://doi.org/ 10.1111/1346-8138.13381

3. Mazzoccoli G, Matarangolo A, Rubino R, Inglese M, De Cata AJC Behçet syndrome: from pathogenesis to novel therapies. Clin Exp Med. 2016;16(1):1-12. https://doi.org/10.1007/s10238-014-0328-z.

4. Behcet HJDW. Uber rezidivierende, aphthose, durchein Virus verusachte Gaschwure am Mund, am Auge und an den Genitalien. Dermat Wochsch. 1937:105:1152-7.

5. Yurdakul S, Hamuryudan V, Yazici HJC. Behçet syndrome. Curr Opin Rheumatol. 2004;16(1):38-42. https://doi.org/10.1097/00002281-20040 1000-00008.

6. Yahalom M, Bloch L, Suleiman K, Rosh B, Turgeman Y. Cardiovascular involvement in Behçet disease: clinical implications. Int J Angiol. 2016:25(5):e84-6. https://doi.org/10.1055/s-0035-1551796.

7. Aksu T, Tufekcioglu O. Intracardiac thrombus in Behçet's disease: four new cases and a comprehensive literature review. Rheumatol Int. 2015;35 (7):1269-79. https://doi.org/10.1007/s00296-014-3174-0.

8. Demirelli S, Degirmenci H, Inci S, Arisoy A. Cardiac manifestations in Behcet's disease. Intractable Rare Dis Res. 2015; 4(2):70-5.https://doi.org/ 10.5582/irdr.2015.01007

9. Petersen SE, Aung N, Sanghvi MM, Zemrak F, Fung K, Paiva JM, et al. Reference ranges for cardiac structure and function using cardiovascular magnetic resonance (CMR) in Caucasians from the UK Biobank population cohort. J Cardiovasc Magn Reson. 2017;19(1):1-19. https://doi.org/ 10.1186/s12968-017-0327-9.

10. Disease ITftRotICfBs, Davatchi F, Assaad-Khalil S, Calamia K, Crook J, Sadeghi-Abdollahi B, et al. The International Criteria for Behçet's Disease (ICBD): a collaborative study of 27 countries on the sensitivity and specificity of the new criteria. J Eur Acad Dermatol Venereol. 2014; 28 (3):338-47. https://doi.org/10.1111/jdv.12107.

11. Henry WL, DeMaria A, Gramiak R, King DL, Kisslo JA, Popp RL, et al. Report of the American Society of Echocardiography Committee on nomenclature and standards in two dimensionalechocardiography. Circulation. 1980;62(2):212-7. https://doi.org/10.1161/01.CIR.62.2.212.

12. Verity D, Marr J, Ohno S, Wallace G, Stanford MJT. Behçet's disease, the Silk Road and HLA-B51: historical and geographical perspectives. Tissue Antigens 1999; 54(3):213-20. https://doi.org/10.1034/j.1399-0039.1999. 540301.x.

13. Yoshimi R. The diagnosis and management of vasculo-Behçet's disease. Intern Med. 2019; 1657-18.https://doi.org/10.2169/internalmedicine. 1657-18.

14. Geri G, Wechsler B, Isnard R, Piette J-C, Amoura Z, Resche-Rigon M, et al. Spectrum of cardiac lesions in Behçet disease: a series of 52 patients and review of the literature. Medicine (Baltimore). 2012;91(1):25-34. https:// doi.org/10.1097/MD.0b013e3182428f49.

15. Seetharam K, Lerakis S. Cardiac magnetic resonance imaging: the future is bright. F1000Res. 2019. https://doi.org/10.12688/f1000research.19721.1.

16. Li R, Pu L, Sun Z, Wang Y, Liu G, Xie J, et al. Echocardiographic findings of cardiovascular involvement in Behçet's disease and post-operative complications after cardiac surgery. Clin Exp Rheumatol. 2018;36(6 Suppl 115):103-9.

17. Aktürk E, Yağmur J, Kurtoğlu E, Ermis N, Acikgoz N, Şener S, et al. Left atrial volume and function in patients with Behcet's disease assessed by real-time three-dimensional echocardiography. Eur Heart J Cardiovasc Imaging. 2012;13(8):650-5. https://doi.org/10.1093/ejechocard/jer301.

18. Pu L, Li R, Xie J, Yang Y, Liu G, Wang Y, et al. Characteristic echocardiographic manifestations of Behçet's disease. Ultrasound Med Biol. 2018; 44(4):825-30. https://doi.org/10.1016/j.ultrasmedbio.2017.12.010.

19. Gao N, Han W, Ci WP, Liao H, Du J. [Clinical data analysis of cardiovascular involvement in Behcet's disease]. Zhonghua Yi Xue Za Zhi.2016; 96 (19):1523-6. https://doi.org/10.3760/cma.j.issn.0376-2491.2016.19.013.

20. Higashihara M, Mori M, Takeuchi A, Ogita T, Miyamoto T, Okimoto T. Myocarditis in Behcet's disease--a case report and review of the literature. J Rheumatol. 1982; 9(4):630-3.
21. Maeda S, Tamura A, Zaizen H, Takahashi NJIM. Behçet's disease complicated by giant-cell myocarditis. Intern Med. 2014;53(15):1721. https://doi. org/10.2169/internalmedicine.53.2213.

22. Lakhanpal S, Tani K, Lie JT, Katoh K, Ishigatsubo Y, Ohokubo T. Pathologic features of Behçet's syndrome: a review of Japanese autopsy registry data. Hum Pathol. 1985;16(8):790-5. https://doi.org/10.1016/S00468177(85)80250-1.

23. Gannon MP, Schaub E, Grines CL, Saba SG. State of the art: evaluation and prognostication of myocarditis using cardiac MRI. J Magn Reson Imaging. 2019; 49(7):e122-e31. https://doi.org/10.1002/jmri.26611.

24. Kechida M, Jomaa W, Maatouk M. A case of behçet disease myocarditis documented using cardiac magnetic resonance imaging. Can J Cardiol. 2020;36(9):1554.e9-.e11. https://doi.org/10.1016/j.cjca.2020.05.006.

25. Pu L, Li R, Xie J, Yang Y, Liu G, Wang Y, et al. Characteristic echocardiographic manifestations of Behcet's disease. Ultrasound Med Biol. 2018:44(4):825-30. https://doi.org/10.1016/j.ultrasmedbio.2017.12.010.

26. Gao N, Han W, Ci W, Liao H, Du J. Clinical data analysis of cardiovascular involvement in Behcet's disease. Zhonghua Yi Xue Za Zhi. 2016;96(19):1523-6. https://doi.org/10.3760/cma.j.issn.0376-2491.2016. 19.013

27. Bletry O, Mohattane A, Wechsler B, Beaufils P, Valere P, Petit J, et al. Cardiac involvement in Behcet's disease. 12 cases. Presse Med. 1988;17 (45):2388-91.

28. Gürgün C, Ercan E, Ceyhan C, Yavuzgil O, Zoghi M, Aksu K, et al. [Cardiovascular involvement in Behçet's disease]. Rev Med Interne. 2014;35(2):103-11. https://doi.org/10.1016/j.revmed.2013.12.002.

29. Gürgün C, Ercan E, Ceyhan C, Yavuzgil O, Zoghi M, Aksu K, et al. Cardiovascular involvement in Behçet's disease. Jpn Heart J. 2002;43(4):389-98. https://doi.org/10.1536/jhj.43.389.

30. Erkan F. Pulmonary involvement in Behçet disease. Curr Opin Pulm Med. 1999; 5(5):314-8. https://doi.org/10.1097/00063198-199909000-00009.

31. Erkan F, Gül A, Tasali E. Pulmonary manifestations of Behçet's disease. Thorax. 2001:56(7):572-8. https://doi.org/10.1136/thx.56.7.572.

32. Hiller N, Lieberman S, Chajek-Shaul T, Bar-Ziv J, Shaham D. Thoracic manifestations of Behçet disease at CT. Radiographics. 2004; 24 (3):801-8. https://doi.org/10.1148/rg.243035091.

33. Liu H-F, Wang M, Xu Y-S, Lu X-R, Lei J-Q. Left circumflex pseudoaneurysm and left anterior descending aneurysm in coronary artery due to Behcet's disease. Chin Med J (Engl). 2018;131(21):2626. https://doi.org/10.4103/ 0366-6999.244119.

34. Farhat SB, Slim M. A coronary artery aneurysm revealing a Behçet's disease: a case report. Pan Afr Med J. 2020. https://doi.org/10.11604/pamj. 2020.36.3.22373.

35. Maatouk M, Messaoud MB, Mnari W, Bouchahda N, Omri F, Gamra H, et al. A giant aneurysm of the left anterior descending coronary artery in the setting of Behcet's disease: case report. Cardiovasc J Afr. 2020; 31(1):e1-e3. https://doi.org/10.5830/CVJA-2019-031.

36. Abou Sherif S, Ozden Tok O, Taşköylü Ö, Goktekin O, Kilic ID. Coronary artery aneurysms: a review of the epidemiology, pathophysiology, diagnosis, and treatment. Front Cardiovasc Med. 2017; 4:24.https://doi.org/10 3389/fcvm.2017.00024

37. Chen H, Zhang Y, Li C, Wu W, Liu J, Zhang F, et al. Coronary involvement in patients with Behçet's disease. Clin Rheumatol. 2019;38(10):2835-41. https://doi.org/10.1007/s10067-019-04640-z.

38. Uyaroglu OA, Erden A, Kilic L, Peynircioğlu B, Karadag O, Kalyoncu U. Behçet's disease; A rare refractory patient with vena cava superior syndrome treated with infliximab: a case report and review of the literature Acta Clin Belg. 2018;74(5):364-9. https://doi.org/10.1080/17843286.2018. 1522020 .

39. Sun BJ, Park JH, Yoo SJ, Park Y, Kim YJ, Lee IS, et al. Intrinsic changes of left ventricular function in patients with Behçet disease and comparison according to systemic disease activity. Echocardiography. 2018;35(6):809_ 16. https://doi.org/10.1111/echo.13844.

\section{Publisher's Note}

Springer Nature remains neutral with regard to jurisdictional claims in published maps and institutional affiliations. 